\title{
Randomized Prospective Comparison of Everolimus-Eluting vs. Sirolimus-Eluting Stents in Patients Undergoing Percutaneous Coronary Intervention -3-Year Clinical Outcomes of the EXCELLENT Randomized Trial -
}

\author{
Kyung Woo Park, MD, PhD; Tae-Min Rhee, MD; Hyun-Jae Kang, MD, PhD; \\ Bon-Kwon Koo, MD, PhD; Hyeon-Cheol Gwon, MD, PhD; Jung-Han Yoon, MD, PhD; \\ Do-Sun Lim, MD, PhD; In-Ho Chae, MD, PhD; Kyoo-Rok Han, MD, PhD; \\ Taehoon Ahn, MD, PhD; Myung-Ho Jeong, MD, PhD; Dong-Woon Jeon, MD, PhD; \\ Yang-Soo Jang, MD, PhD; Hyo-Soo Kim, MD, PhD
}

\begin{abstract}
Background: Everolimus-eluting stents (EES) have equivalent short-term angiographic and clinical outcomes to sirolimus-eluting stents (SES), but EES may be superior to SES with regard to long-term clinical safety. We report the 3-year clinical outcomes of EES and SES from the prospective EXCELLENT Randomized Trial (NCT00698607).

Methods and Results: We randomly assigned 1,443 patients undergoing percutaneous coronary intervention 3:1 to receive EES and SES, respectively. We investigated endpoints including target lesion failure (TLF) and individual clinical outcomes including stent thrombosis (ST) at 3 years. For EES and SES, the TLF rate was $4.82 \%$ and $4.12 \%$ (risk ratio [RR], 1.16, 95\% Cl: 0.65-2.06, P=0.62), respectively. Results were similar in other efficacy endpoints including target lesion revascularization. For safety endpoints, rate of all-cause death was significantly lower for EES (1.67\%) than SES (3.57\%; RR, 0.46; 95\% Cl: $0.23-0.94, P=0.03$ ), while the incidence of cardiac death or myocardial infarction was numerically lower in EES. On 1-year landmark analysis, rates of all-cause death and major adverse cardiovascular events were significantly lower for EES than SES. Definite or probable ST was numerically 3-fold higher for SES $(1.37 \%)$ compared with EES $(0.46 \%)$.
\end{abstract}

Conclusions: EES and SES had similar efficacy with regard to 3-year outcomes in the EXCELLENT trial, while delayed safety events all trended to favor EES.

Key Words: Everolimus; Percutaneous coronary intervention; Sirolimus; Stent

D rug-eluting stents (DES) have revolutionized the field of percutaneous coronary intervention (PCI). ${ }^{1,2}$ First-generation DES, however, such as paclitaxelor sirolimus-eluting stents (SES), have potential long-term problems such as delayed healing, leading to risk of very late stent thrombosis (ST). ${ }^{3-5}$ Second-generation DES with a thinner strut and biocompatible polymer coating, such as everolimus-eluting stents (EES), have possible long-term

\section{Editorial p 1497}

advantages in safety compared with first-generation DES. ${ }^{6.8}$

We previously reported the 1-year outcome of the Efficacy of Xience/promus vs. Cypher in rEducing Late Loss after stenting (EXCELLENT) Trial, comparing SES with EES. We analyzed 9-month in-segment lumen loss as a

Received June 19, 2017; revised manuscript received August 18, 2017; accepted September 1, 2017; released online September 30, 2017 Time for primary review: 24 days

Department of Internal Medicine and Cardiovascular Center, Seoul National University Hospital, Seoul (K.W.P., T.-M.R., H.-J.K., B.-K.K., H.-S.K.); Sung-Kyun-Kwan University Samsung Medical Center, Seoul (H.-C.G.); Yonsei University Wonju Severance Hospital, Wonju (J.-H.Y.); Korea University Anam Hospital, Seoul (D.-S.L.); Seoul National University Bundang Hospital, Seongnam (I.-H.C.); Kangdong Sacred Heart Hospital, Seoul (K.-R.H.); Gachon University Gil Medical Center, Incheon (T.A.); Chonnam National University Hospital, Gwangju (M.-H.J.); NHIC Ilsan Hospital, Ilsan (D.-W.J.); and Yonsei University Severance Hospital, Seoul (Y.-S.J.), Korea

The first two authors contributed equally to this work (K.W.P., T.-M.R.).

Mailing address: Hyo-Soo Kim, MD, PhD, Department of Internal Medicine, Cardiovascular Center, Seoul National University Hospital, 101 Daehak-ro, Jongro-gu, Seoul 03080, Korea. E-mail: hyosoo@snu.ac.kr

ISSN-1346-9843 All rights are reserved to the Japanese Circulation Society. For permissions, please e-mail: cj@j-circ.or.jp 
primary endpoint and other clinical outcomes including target lesion failure (TLF), showing that EES was noninferior compared with SES up to 1 year. ${ }^{9}$ In that report, although it did not reach statistical significance, safety endpoints such as cardiac death, myocardial infarction (MI) and ST had a tendency to favor EES.

We now report the long-term 3-year clinical outcomes of the EXCELLENT trial, focusing specifically on the delayed adverse events after 1 year.

\section{Methods}

Extended description of the study methods is presented in the Supplementary File 1.

\section{Study Design, Subjects, and Procedures}

The EXCELLENT trial was a prospective, randomized, multicenter trial that enrolled 1,443 patients between June 2008 and July 2009 in order to compare the efficacy of EES vs. SES in reducing late loss in patients undergoing PCI. The study design, eligibility or exclusion criteria, and the primary results including 1-year clinical outcomes have been reported previously. ${ }^{9}$ In brief, all patients were randomly assigned 3:1 to receive EES (Xience V; Abbott Vascular, Santa Clara, CA, USA; and Promus; Boston Scientific, Natick, MA, USA) or SES (Cypher Select; Cordis, Bridgewater, NJ, USA), respectively. Randomization was conducted using a Web-based online randomization system after diagnostic angiography and before PCI. Randomization was stratified according to enrolling sites, the presence of diabetes, and long lesions. The study protocol was approved by the ethics committee at each participating center and was conducted according to the principles of the Declaration of Helsinki. All patients provided written informed consent for participation in the trial.

Balloon angioplasty and stent implantation were performed according to standard techniques. It was recommended that all significant lesions be fully covered by one or multiple stents using the same randomly assigned stent, except when the allocated stent could not be inserted or was not suitable for the lesion, in which case cross-over to another device at the discretion of the operator was permitted. Before the index procedure, all patients received $\geq 300 \mathrm{mg}$ aspirin and a 300-600-mg loading dose of clopidogrel. After the procedure, all patients were maintained with aspirin $(\geq 75 \mathrm{mg} /$ day $)$ indefinitely and clopidogrel $(75 \mathrm{mg} /$ day) for at least 6 months.

\section{Follow-up and Data Collection}

After the index PCI, clinical follow-up was performed at 1, $3,9,12,24$ and 36 months. For evaluation of the angiographic endpoints, all patients were recommended to undergo angiographic follow-up at 9 months. Patients were followed up by telephone contact or office visit. At followup, patients were specifically questioned regarding the occurrence of any adverse events or the presence of angina symptoms.

\section{Study Endpoints}

The 3-year clinical endpoints analyzed in this study included TLF (a composite of cardiac death, target-vessel MI, and ischemia-driven target lesion revascularization [TLR]), individual components of TLF, all-cause death, any MI, any repeat revascularization, ischemia-driven target vessel revascularization (TVR), and ST defined as definite or

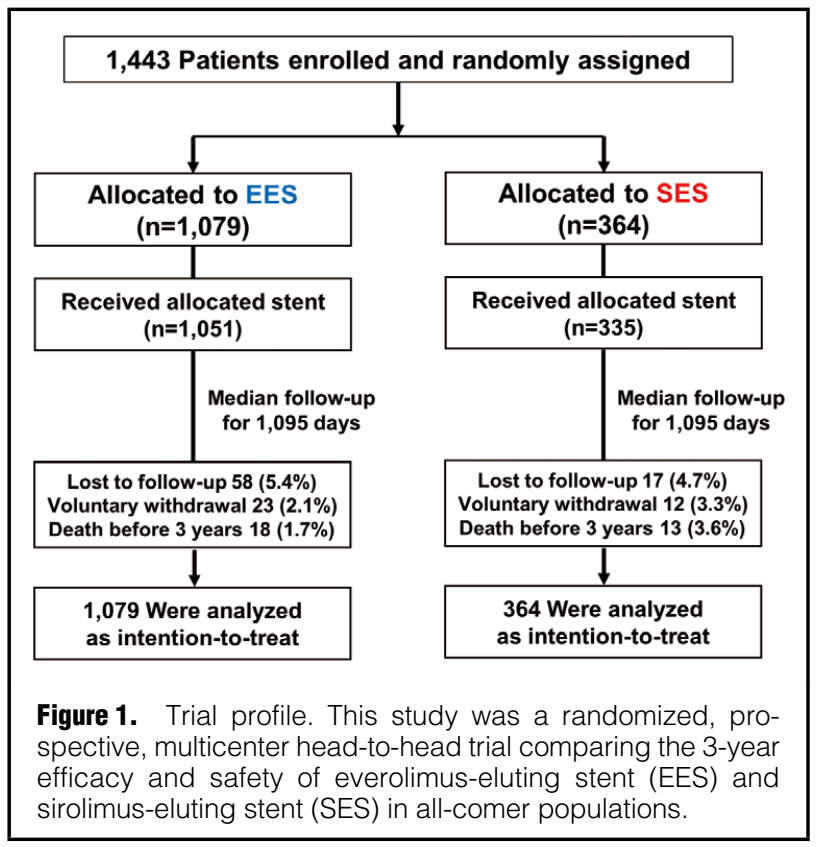

probable according to the Academic Research Consortium (ARC) definitions. ${ }^{10}$ Other composite endpoints that focused on the safety were also analyzed, including patientoriented composite outcome (a composite of all-cause death, any MI, and any repeat revascularization), death or MI, cardiac death or target-vessel MI, and major adverse cardiovascular events (MACE; a composite of all-cause death, any MI, and definite or probable ST). Data were managed by an independent management center (Medical Research Collaborating Center, Seoul National University Hospital, Seoul, Korea), and all clinical events were adjudicated by an independent adjudication committee.

\section{Statistical Analysis}

Baseline data are presented as frequencies or mean \pm SD. Categorical variables were compared using the chi-squared or Fischer's exact tests, while continuous variables were compared using Student's t-test. The event-free survival rates were analyzed using the Kaplan-Meier method, and the comparison of clinical outcomes between EES and SES was performed with the log-rank test. Analysis of independent predictors for TLF and death or MI was performed using a multivariable Cox proportional hazard regression model. The covariates were selected if they were significantly different between the 2 groups $(\mathrm{P}<0.1)$, or if they had predictive value. Covariates included in the model predicting TLF were stent type (EES or SES), age increase per 10 years, hypertension, diabetes mellitus, previous history of stroke, current smoker, congestive heart failure, long lesion ( $\geq 28 \mathrm{~mm}$ ), multivessel stenting, and bifurcation treated by 2 stents. Covariates included in the model predicting death or MI were stent type, age increase per 10 years, hypertension, diabetes mellitus, peripheral vascular disease, congestive heart failure, previous PCI, previous MI, chronic kidney disease, and multivessel disease. C-statistics with 95\% CI were calculated to validate the discriminant function of the model. For subgroup analyses, comparisons for the efficacy endpoint (TLF) and safety endpoint (death or MI) between EES and SES according to the pre-specified subgroups 


\begin{tabular}{|c|c|c|c|c|}
\hline & $\begin{array}{c}\text { Total } \\
(n=1,443)\end{array}$ & $\begin{array}{c}\text { EES } \\
(n=1,079)\end{array}$ & $\begin{array}{c}\text { SES } \\
(n=364)\end{array}$ & P-value \\
\hline \multicolumn{5}{|l|}{ Demographic features } \\
\hline Age (years) & $62.7 \pm 10.0$ & $62.5 \pm 10.1$ & $63.4 \pm 9.9$ & 0.12 \\
\hline Men & $931(64.5)$ & $703(65.2)$ & $228(62.6)$ & 0.39 \\
\hline $\mathrm{BMI}\left(\mathrm{kg} / \mathrm{m}^{2}\right)$ & $25.0 \pm 3.1$ & $25.0 \pm 3.1$ & $25.0 \pm 2.9$ & 0.89 \\
\hline \multicolumn{5}{|l|}{ Cardiovascular risk factors } \\
\hline Hypertension & 1,057 (73.3) & 791 (73.3) & $266(73.1)$ & 0.93 \\
\hline Diabetes mellitus & $550(38.1)$ & $402(37.3)$ & $148(40.7)$ & 0.25 \\
\hline Dyslipidemia & $1,093(75.7)$ & $823(76.3)$ & $270(74.2)$ & 0.42 \\
\hline Current smoker & $384(26.6)$ & $278(25.8)$ & $106(29.1)$ & 0.21 \\
\hline Previous MI & $74(5.1)$ & $56(5.2)$ & $18(4.9)$ & 0.85 \\
\hline Previous $\mathrm{PCl}$ & $129(8.9)$ & $99(9.2)$ & $30(8.2)$ & 0.59 \\
\hline Previous CABG & $18(1.2)$ & $12(1.1)$ & $6(1.6)$ & 0.42 \\
\hline Previous CVA & $95(6.6)$ & $58(5.4)$ & $37(10.2)$ & $<0.01$ \\
\hline PAD & $19(1.3)$ & $13(1.2)$ & $6(1.6)$ & 0.59 \\
\hline Multivessel disease & $750(52.0)$ & $564(52.3)$ & $186(51.1)$ & 0.70 \\
\hline LVEF (\%) & $61.3 \pm 9.5$ & $61.4 \pm 9.4$ & $60.8 \pm 9.8$ & 0.33 \\
\hline Clinical indication of $\mathrm{PCl}$ & & & & 0.12 \\
\hline Stable angina & $644(44.6)$ & $472(43.7)$ & $172(47.3)$ & \\
\hline Unstable angina & $601(41.6)$ & $464(43.0)$ & $137(37.6)$ & \\
\hline NSTEMI & $98(6.8)$ & $76(7.0)$ & $22(6.0)$ & \\
\hline STEMI & $45(3.1)$ & $28(2.6)$ & $17(4.7)$ & \\
\hline Silent ischemia & $55(3.8)$ & $39(3.6)$ & $16(4.4)$ & \\
\hline \multicolumn{5}{|l|}{ Medication at discharge } \\
\hline Aspirin & $1,411(99.2)$ & $1,061(99.3)$ & $350(98.9)$ & 0.48 \\
\hline Clopidogrel & $1,410(99.2)$ & $1,058(99.1)$ & $352(99.4)$ & 0.74 \\
\hline Statin & $1,186(83.4)$ & $888(83.1)$ & $298(84.2)$ & 0.65 \\
\hline ACEI & $467(32.8)$ & 352 (33) & $115(32.5)$ & 0.87 \\
\hline ARB & $475(33.4)$ & $355(33.2)$ & $120(33.9)$ & 0.82 \\
\hline$\beta$-blocker & $872(61.3)$ & $660(61.8)$ & $212(59.9)$ & 0.52 \\
\hline $\mathrm{CCB}$ & 487 (34.2) & $360(33.7)$ & $127(35.9)$ & 0.46 \\
\hline
\end{tabular}

Data given as mean $\pm S D$ or $n(\%)$. ACEI, angiotensin-converting enzyme inhibitor; ARB, angiotensin II receptor blocker; BMI, body mass index; CABG, coronary artery bypass graft; CCB, calcium channel blocker; CHF, congestive heart failure; CVA, cerebrovascular accident; EES, everolimus-eluting stent; LVEF, left ventricular ejection fraction; MI, myocardial infarction; NSTEMI, non ST-segment elevation myocardial infarction; PAD, peripheral artery disease; $\mathrm{PCl}$, percutaneous coronary intervention; SES, sirolimus-eluting stent; STEMI, ST-segment elevation myocardial infarction.

were followed, and interaction between the treatment and each subgroup was assessed with Cox proportional hazard models. All clinical outcomes were analyzed on an intention-to-treat basis. Patients treated with SES were defined as the reference group. All probability values were 2 -sided, and $\mathrm{P}<0.05$ was considered statistically significant. Analyses were performed using SPSS version 19.0 for Windows (SPSS, Chicago, IL, USA).

\section{Results}

\section{Baseline Characteristics}

A total of 1,443 patients (1,927 lesions) were enrolled in the study and randomly assigned to receive EES $(n=1,079$; 1,459 lesions) or SES ( $n=364 ; 468$ lesions; Figure 1). The median follow-up duration was 1,095 days, and 1,368 patients $(94.8 \%)$ completed a 3-year follow-up; 1,021 of $1,079(94.6 \%)$ in the EES group and 347 of $364(95.3 \%)$ in the SES group. Baseline patient, lesion, and procedural characteristics are listed in Tables 1,2. Most baseline characteristics were similar between the EES and SES groups except for the history of cerebrovascular accident, number of implanted stents per patient, and final balloon pressure.

\section{Three-Year Clinical Outcomes}

The cumulative 3-year clinical outcomes are listed in Table 3. The incidence of TLF was $4.82 \%$ for EES and $4.12 \%$ for SES, which was not significantly different (risk ratio $[R R], 1.16 ; 95 \% \mathrm{CI}$ : 0.65-2.06, $\mathrm{P}=0.62$; Figure 2). Rates of ischemia-driven TVR (RR, 1.27 ; 95\% CI: $0.66-$ 2.47, $\mathrm{P}=0.48)$ and TLR (RR, 1.41; 95\% CI: 0.65-3.05, $\mathrm{P}=0.38$ ) also showed similar trends. In a landmark analysis from 1 year, the occurrence of TLF from 1 to 3 years was similar ( $\mathrm{RR}, 1.01$; 95\% CI: $0.33-3.15, \mathrm{P}=0.98$ ), and the efficacy outcomes including TVR and TLR were similar (Table S1).

For safety endpoints, the differences between the 2 groups were more prominent. The rate of all-cause death was significantly lower in EES (1.67\%) than in SES $(3.57 \%$; RR, 0.46; 95\% CI: 0.23-0.94, P=0.03; Figure 3). The incidence of death or MI, MACE, cardiac death, and target- 


\begin{tabular}{|c|c|c|c|c|}
\hline & $\begin{array}{c}\text { Total } \\
(n=1,927)\end{array}$ & $\begin{array}{c}\text { EES } \\
(n=1,459)\end{array}$ & $\begin{array}{c}\text { SES } \\
(n=468)\end{array}$ & P-value ${ }^{\dagger}$ \\
\hline \multicolumn{5}{|l|}{ Before index procedure } \\
\hline Location of target lesion & & & & 0.79 \\
\hline LAD & $956(49.8)$ & $721(49.6)$ & $235(50.4)$ & \\
\hline LCX & $421(21.9)$ & $320(22.0)$ & $101(21.7)$ & \\
\hline $\mathrm{RCA}$ & $542(28.2)$ & $412(28.3)$ & $130(27.9)$ & \\
\hline Coronary graft & $1(0.1)$ & $1(0.1)$ & $0(0.0)$ & \\
\hline ACC/AHA B2 or C type & $991(53.3)$ & $746(53.0)$ & $245(54.2)$ & 0.62 \\
\hline Total occlusion & $66(3.5)$ & $48(3.4)$ & $18(4.0)$ & 0.58 \\
\hline Thrombus-containing & $147(7.9)$ & $114(8.1)$ & $33(7.3)$ & 0.57 \\
\hline Bifurcation lesions & $209(10.8)$ & $155(10.6)$ & $54(11.5)$ & 0.54 \\
\hline Calcification & $772(41.4)$ & $589(41.7)$ & $183(40.4)$ & 0.64 \\
\hline MLD (mm) & $0.87 \pm 0.48$ & $0.87 \pm 0.48$ & $0.88 \pm 0.50$ & 0.68 \\
\hline $\mathrm{RVD}(\mathrm{mm})$ & $2.88 \pm 0.50$ & $2.87 \pm 0.49$ & $2.88 \pm 0.52$ & 0.65 \\
\hline Diameter stenosis (\%) & $69.7 \pm 15.3$ & $69.7 \pm 15.3$ & $69.6 \pm 15.4$ & 0.94 \\
\hline Lesion length (mm) & $20.4 \pm 11.9$ & $20.3 \pm 12.1$ & $20.5 \pm 11.5$ & 0.80 \\
\hline \multicolumn{5}{|l|}{ After index procedure } \\
\hline No. stents per lesion & $1.21 \pm 0.46$ & $1.21 \pm 0.47$ & $1.19 \pm 0.42$ & 0.26 \\
\hline No. stents per patient & $1.61 \pm 0.95$ & $1.64 \pm 0.97$ & $1.53 \pm 0.86$ & $0.04 \S$ \\
\hline Total stent length/lesion (mm) & $28.1 \pm 13.4$ & $27.9 \pm 13.5$ & $28.5 \pm 13.2$ & 0.43 \\
\hline Total stent length/patient $(\mathrm{mm})$ & $37.5 \pm 25.0$ & $37.8 \pm 25.1$ & $36.8 \pm 24.7$ & $0.50 \S$ \\
\hline Glycoprotein Ilb/IIla inhibitors & $24(1.7)$ & $19(1.8)$ & $5(1.4)$ & $0.62^{\ddagger}$ \\
\hline Final balloon pressure (atm) & $14.3 \pm 3.63$ & $14.1 \pm 3.57$ & $15.0 \pm 3.72$ & $<0.01$ \\
\hline IVUS & $627(43.5)$ & $467(43.3)$ & $160(44)$ & $0.82^{\ddagger}$ \\
\hline Lesion success & $1,905(99.7)$ & $1,445(99.7)$ & $460(99.8)$ & 0.82 \\
\hline Device success & $1,904(99.7)$ & $1,447(99.9)$ & $457(99.1)$ & 0.10 \\
\hline Procedure success & $1,891(99.0)$ & $1,434(99.0)$ & $457(99.1)$ & 0.93 \\
\hline
\end{tabular}

Data given as mean $\pm \mathrm{SD}$ or $\mathrm{n}(\%)$. ${ }^{\dagger}$ Calculated using generalized estimating equations except for per-patient comparisons, which were calculated using $¥$ chi-squared test or §Student t-test. ACC/AHA, American College of Cardiology/American Heart Association; IVUS, intravascular ultrasound; LAD, left anterior descending artery; LCX, left circumflex artery; MLD, minimum lumen diameter; RCA, right coronary artery; RVD, reference vessel diameter. Other abbreviations as in Table 1.

Table 3. Clinical Outcomes at 3 Years in the Intention-to-Treat Population

\begin{tabular}{|c|c|c|c|c|c|}
\hline & $\begin{array}{c}\text { Total } \\
(n=1,443)\end{array}$ & $\begin{array}{c}\text { EES } \\
(n=1,079)\end{array}$ & $\begin{array}{c}\text { SES } \\
(n=364)\end{array}$ & $\begin{array}{c}\text { RR } \\
(95 \% \mathrm{Cl})^{\dagger}\end{array}$ & P-value \\
\hline All-cause death & $2.15(31)$ & $1.67(18)$ & $3.57(13)$ & $0.46(0.23-0.94)$ & 0.03 \\
\hline Cardiac death & $0.76(11)$ & $0.56(6)$ & $1.37(5)$ & $0.40(0.12-1.31)$ & 0.13 \\
\hline Non-cardiac death & $1.39(20)$ & $1.11(12)$ & $2.20(8)$ & $0.50(0.20-1.22)$ & 0.13 \\
\hline Any MI & $1.80(26)$ & $1.67(18)$ & $2.20(8)$ & $0.75(0.33-1.73)$ & 0.50 \\
\hline Target-vessel MI & $1.59(23)$ & $1.39(15)$ & $2.20(8)$ & $0.63(0.27-1.48)$ & 0.29 \\
\hline MI due to ST & $0.49(7)$ & $0.28(3)$ & $1.10(4)$ & $0.25(0.06-1.11)$ & 0.07 \\
\hline Any repeat revascularization & $7.69(111)$ & $7.88(85)$ & $7.14(26)$ & $1.09(0.70-1.68)$ & 0.72 \\
\hline Ischemia-driven TVR & $3.67(53)$ & $3.89(42)$ & $3.02(11)$ & $1.27(0.66-2.47)$ & 0.48 \\
\hline Ischemia-driven TLR & $2.91(42)$ & $3.15(34)$ & $2.20(8)$ & $1.41(0.65-3.05)$ & 0.38 \\
\hline Definite ST & $0.55(8)$ & $0.37(4)$ & $1.10(4)$ & $0.33(0.08-1.33)$ & 0.12 \\
\hline Definite or probable ST & $0.69(10)$ & $0.46(5)$ & $1.37(5)$ & $0.33(0.10-1.15)$ & 0.08 \\
\hline Cerebrovascular accident & $0.97(14)$ & $0.83(9)$ & $1.37(5)$ & $0.60(0.20-1.78)$ & 0.35 \\
\hline TIMI major bleeding & $0.83(12)$ & $0.83(9)$ & $0.82(3)$ & $1.02(0.28-3.77)$ & 0.98 \\
\hline Target lesion failure $\ddagger$ & $4.64(67)$ & $4.82(52)$ & $4.12(15)$ & $1.16(0.65-2.06)$ & 0.62 \\
\hline Patient-oriented composite outcome $\S$ & $10.67(154)$ & $10.47(113)$ & $11.26(41)$ & $0.92(0.64-1.31)$ & 0.64 \\
\hline Death or MI & $3.74(54)$ & $3.24(35)$ & $5.22(19)$ & $0.62(0.35-1.07)$ & 0.09 \\
\hline Cardiac death or target-vessel MI & $2.22(32)$ & $1.95(21)$ & $3.02(11)$ & $0.64(0.31-1.32)$ & 0.23 \\
\hline MACEף & 3.95 (57) & $3.43(37)$ & $5.49(20)$ & $0.62(0.36-1.06)$ & 0.08 \\
\hline
\end{tabular}

Data given as \% (n). tRisk ratios were calculated using Cox regression modeling with the SES group as a reference. Median follow-up duration was 1,095 days. $¥$ Composite of cardiac death, target-vessel MI, and ischemia-driven TLR. \$Composite of all-cause death, any MI, and any repeat revascularization. "Composite of all-cause death, any MI, and definite or probable ST. MACE, major adverse cardiovascular event; RR, risk ratio; ST, stent thrombosis; TIMI, Thrombolysis in Myocardial Infarction; TLR, target lesion revascularization; TVR, target vessel revascularization. Other abbreviations as in Table 1. 
A

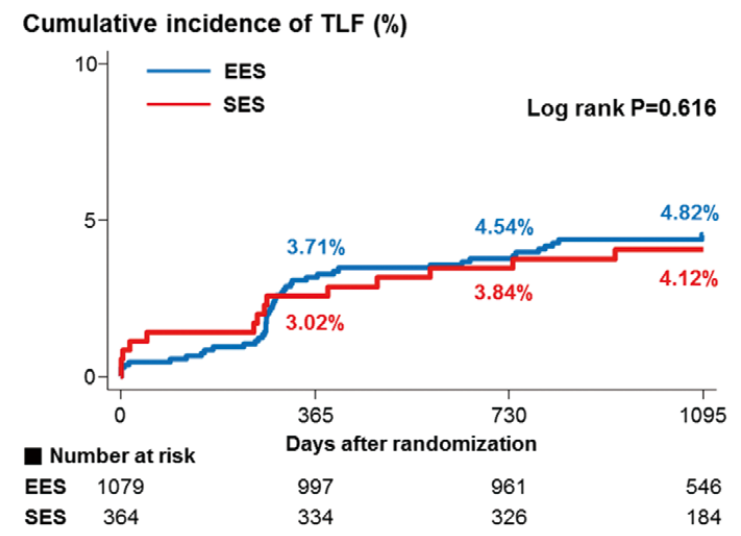

C

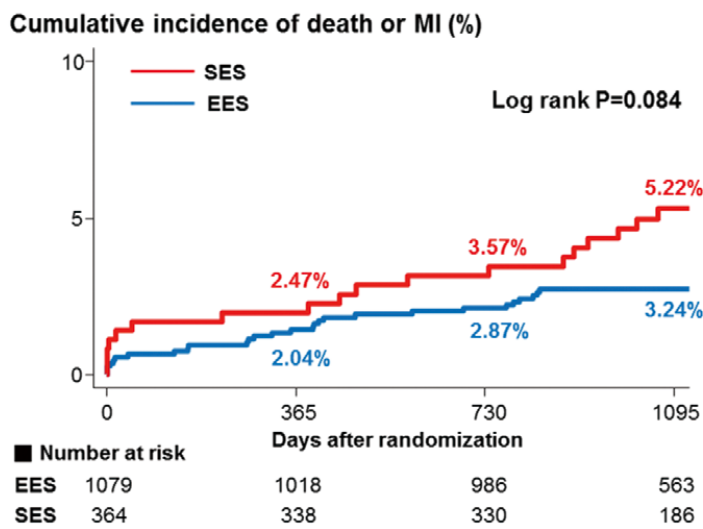

B

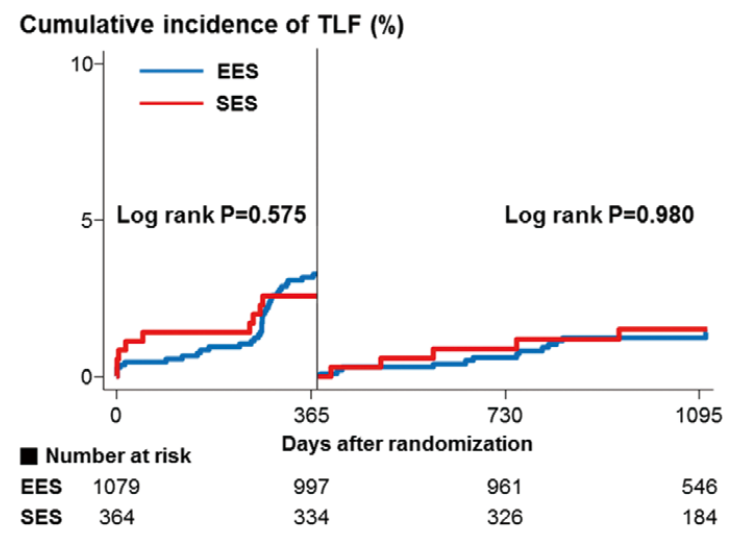

D

Cumulative incidence of death or $\mathrm{MI}(\%)$

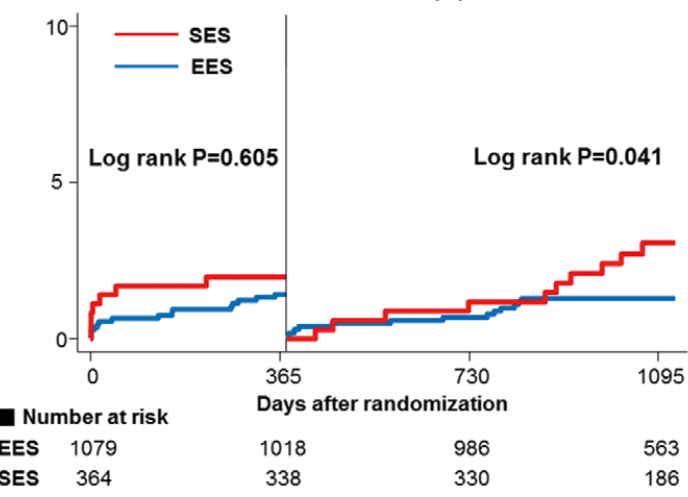

Figure 2. Kaplan-Meier $(\mathbf{A}, \mathbf{C})$ cumulative event curves up to 3 years and (B,D) 1-year landmark analysis of $(\mathbf{A}, \mathbf{B})$ target lesion failure (TLF) and (C,D) death or myocardial infarction (MI) for everolimus-eluting stent (EES) vs. sirolimus-eluting stent (SES).

vessel MI were numerically lower in the EES group than in the SES group, although this did not reach statistical significance. From 1 to 3 years, however, rates of death or MI, MACE, and all-cause death were significantly lower in the EES group. Although non-significant, the rates of cardiac death or target-vessel MI were also lower in EES, with 3-4-fold numerical difference.

Rates of definite or probable ST at 3 years was $0.46 \%$ vs. $1.37 \%$ for EES vs. SES (RR, 0.33 ; 95\% CI: $0.10-1.15$, $\mathrm{P}=0.08)$. Very late $\mathrm{ST}$ was rare but its rate was numerically higher in the SES group $(0.09 \%$ vs. $0.55 \%$ for EES vs. SES, $\mathrm{P}=0.14)$. MI due to ST also showed a trend favoring EES over SES (RR, 0.25 ; 95\% CI: 0.06-1.11, P=0.07). One case of very late ST from EES presented as MI but the patient completely recovered. Both patients with very late ST in SES, however, died due to cardiac cause (Figure 4).

Dual antiplatelet therapy was maintained in $55.0 \%$, $17.3 \%$, and $12.1 \%$ at 1,2 , and 3 years, respectively. The mean duration of dual antiplatelet therapy was not different between the 2 groups (Table $\mathbf{S 2}$ ).

\section{Independent Predictors of Efficacy and Safety Endpoints}

A multivariable Cox regression model was used to identify independent predictors of TLF and death or MI (Table 4). For both the efficacy and safety endpoints, congestive heart failure (TLF: adjusted RR, 10.29; 95\% CI: 3.212-32.97, $\mathrm{P}<0.001$; death or MI: adjusted RR, 7.459; 95\% CI: $2.246-$ $24.77, \mathrm{P}=0.001)$ was the strongest predictor outcome. Use of SES (EES as a reference group) had no effect on the occurrence of TLF, but marginally increased the risk of death or MI (adjusted RR, 1.601; 95\% CI: 0.900-2.847, $\mathrm{P}=0.109$ ) without statistical significance.

\section{Subgroup Analysis}

For the efficacy endpoint of TLF and safety endpoint of death or MI, subgroup analyses were performed for diabetes, renal dysfunction with estimated creatinine clearance $<60 \mathrm{~mL} / \mathrm{min}$, acute MI, multivessel stenting, long lesion, and reference vessel diameter $<2.75 \mathrm{~mm}$. The results of efficacy and safety outcomes between EES and SES were consistent across all subgroups, with no significant interaction P-values (Figure S1).

\section{Discussion}

Three-year outcomes from the randomized, prospective EXCELLENT trial showed that the cumulative rates of TLF was low in both the EES and SES groups, and the clinical efficacy of both stents represented by ischemiadriven TLR or TVR was similar. As for safety outcomes, 
A

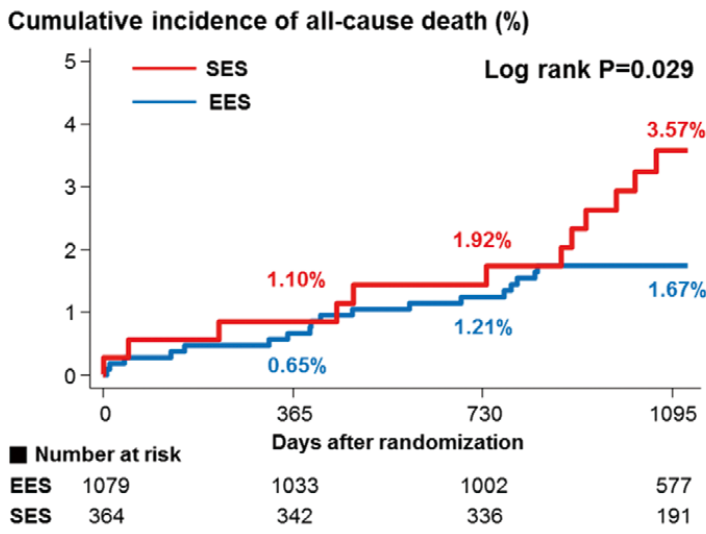

C

Cumulative incidence of target-vessel MI (\%)

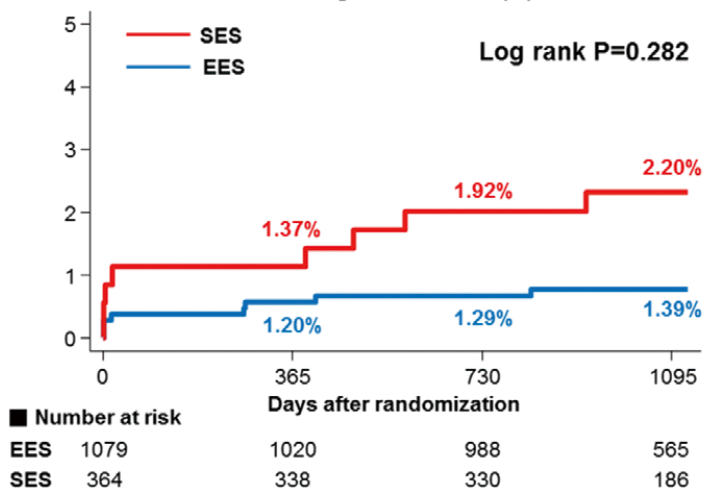

B

Cumulative incidence of cardiac death (\%)

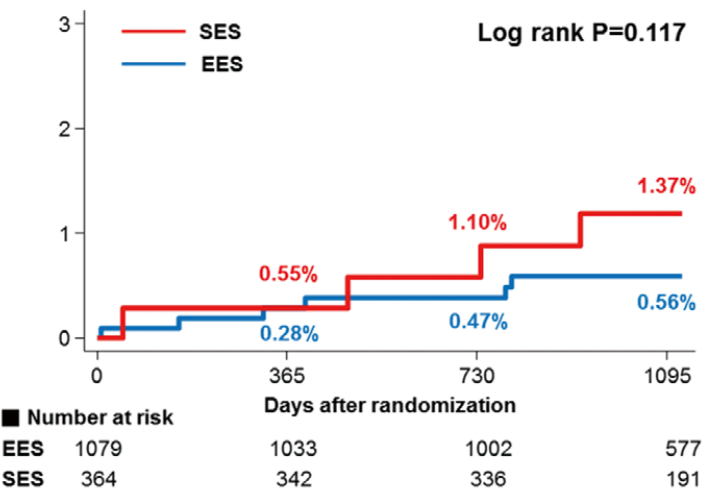

D

Cumulative incidence of TLR (\%)

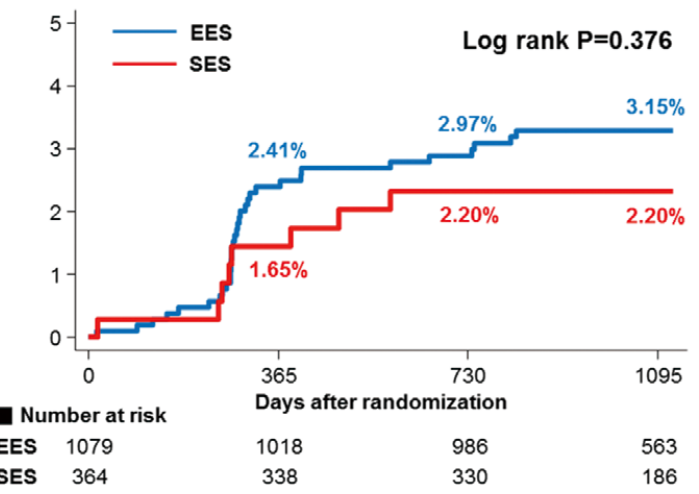

Figure 3. Kaplan-Meier cumulative event curves up to 3 years for $(\mathbf{A})$ all-cause death, $(\mathbf{B})$ cardiac death, (C) target-vessel myocardial infarction (MI), and (D) ischemia-driven target lesion revascularization (TLR) for everolimus-eluting stent (EES) vs. sirolimus-eluting stent (SES).

cardiac death and target-vessel MI were numerically lower in EES than in SES, although not statistically significant. Despite the lack of sufficient power to validate differences in clinical outcomes, rates of all-cause death at 3 years and death or MI and MACE at 1-3 years were significantly lower in the EES group. Definite or probable ST and very late ST also favored the EES group, and had a 2-3-fold numerical difference without statistical significance, suggesting that although efficacy outcomes are similar between EES and SES, EES may have superior long-term safety outcomes.

Among the first-generation DES, SES was the most widely used stent and had the best outcomes. ${ }^{\mathbf{1 1}, 12}$ Therefore, although SES is no longer used in routine clinical practice, it is still the standard against which second-generation DES should be judged. In comparing the performance of SES and EES, the head-to-head randomized trials in allcomer populations reported to date have shown similar efficacy and safety. The possibility of delayed adverse events particularly in SES has been raised, but the results are controversial.

In this study, the efficacy outcomes including TLF were equivalent in the EES and SES groups, and similar results were obtained in the 5-year results of the ISAR-TEST 4

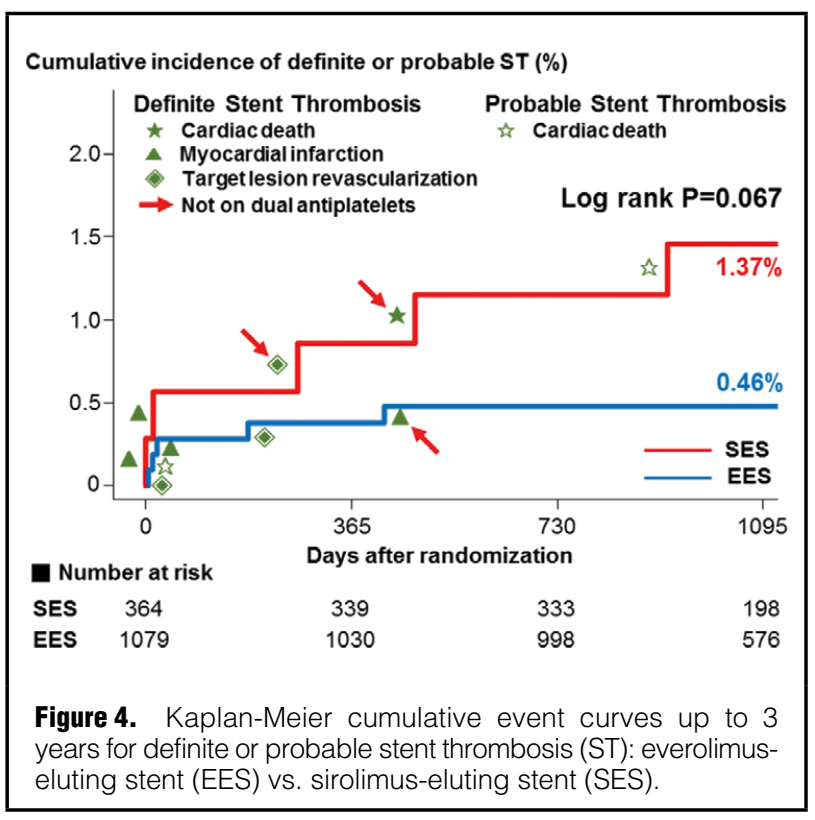

Circulation Journal Vol.82, June 2018 


\begin{tabular}{|c|c|c|c|}
\hline & Adjusted risk ratio & $95 \% \mathrm{Cl}$ & P-value \\
\hline \multicolumn{4}{|l|}{ Predictors of TLF $\ddagger$} \\
\hline Congestive heart failure & 10.29 & $3.212-32.97$ & $<0.001$ \\
\hline Multivessel stenting & 1.960 & $1.171-3.281$ & 0.010 \\
\hline Bifurcation treated by 2 stents & 1.776 & $1.135-2.778$ & 0.012 \\
\hline SES use (EES as a reference) & 0.950 & $0.528-1.711$ & 0.865 \\
\hline \multicolumn{4}{|l|}{ Predictors of death or MI } \\
\hline Congestive heart failure & 7.459 & $2.246-24.77$ & 0.001 \\
\hline Diabetes mellitus & 2.582 & $1.490-4.475$ & 0.001 \\
\hline Age increase per 10 years & 1.777 & $1.341-2.355$ & $<0.001$ \\
\hline SES use (EES as a reference) & 1.601 & $0.900-2.847$ & 0.109 \\
\hline
\end{tabular}

†Multivariable Cox proportional hazard regression modeling. Harrel's c-index was 0.675 (95\% Cl: 0.612-0.739) for TLF, and 0.628 ( $95 \% \mathrm{Cl}: 0.566-0.690)$ for death or MI. ₹Composite of cardiac death, target-vessel $\mathrm{Ml}$, and ischemiadriven TLR. TLF, target lesion failure. Other abbreviations as in Tables 1,3.

trial. ${ }^{13}$ In RESET and SORT OUT IV trials, long-term efficacy has been shown to slightly favor EES. ${ }^{14,15}$ Although the present results support the excellent long-term efficacy of SES and its similarity to that of EES, it should be noted that the 3:1 randomization protocol may have led to underestimation of event rate in the SES group because the number of patients in the SES group was low. Furthermore, the patients were in general at lower risk compared with other trials, and therefore, the proportion of complex lesions was also low. The well-known advantages of EES and its superior efficacy in high-risk patients and complex lesions may not have been evident in the present study. Finally, we cannot completely rule out the possibility of undetected repeat revascularization events in those lost to follow-up.

For safety endpoints such as cardiac death, target-vessel MI and ST, the results were numerically favorable for EES rather than SES, although not statistically significant. In most of the previous trials, the long-term safety outcomes were consistent with the present study. In ISAR-TEST 4 the rates of cardiac death, target-vessel MI, and ST were numerically lower in the EES group. ${ }^{13}$ In SORT OUT IV, marginally lower target-vessel MI and significantly lower definite or probable ST, very late ST, and MACE rates were observed in the EES group. ${ }^{15}$ In contrast, in the RESET trial all safety outcomes including even ST were equivalent in EES and SES. More than two-thirds of patients, however, had maintained dual antiplatelet therapy up to 3 years, and the rate of intravascular ultrasound (IVUS)-guided PCI was high in the RESET trial. ${ }^{14}$ Notably, in the present study, incidence of all-cause death was significantly lower in EES at both 3-year and 1-year landmark analysis. In addition to cardiac death, EES has shown favorable results in non-cardiac deaths as well, resulting in the significant difference in all-cause death. Considering, however, the relatively small number of patients in the SES group due to 3:1 randomization, this difference may have occurred by chance and should be interpreted with caution.

In the present study, major clinical outcomes including efficacy and safety endpoints were overall lower than in other randomized trials, but there may be several reasons for these differences. First, clinical event rates in interventional clinical trials are in general lower in trials performed in East Asian patients. Furthermore, in this trial, the proportion of high-risk patients was significantly lower compared with other randomized trials. In particular, the proportion of patients with a history of previous MI, previous PCI or bypass surgery, or those presenting with ST-elevation MI was significantly lower. This may have had a great impact on the lower rates of mortality, MI, or repeat revascularization in this study. Second, the present 3 -year follow-up rate was $94.6 \%$, which was slightly lower than in other trials. This can raise the possibility of underreporting. The present adverse event data, however, were systematically collected and managed by an independent institution (Medical Research Collaborating Center, Seoul National University Hospital, Seoul, Korea), and followup of the patients who did not visit the hospital was rigorously done at each center via direct telephone contact. In addition, using the unique personal identification numbers of the Korean nationwide health-care system, the vital status of $100 \%$ of patients was cross-checked and fully confirmed even in patients who were lost to follow-up. In this way, the possibility of under-reporting of bias was minimized.

The 3-year rate of definite or probable ST in EES was $0.5 \%$ in this study, and $0.7 \%, 0.7 \%$, and $1.4 \%$ in RESET, ${ }^{14}$ SORT OUT IV,${ }^{15}$ and ISAR-TEST $4,{ }^{13}$ respectively. In addition to the extremely low incidence of ST, most ST events occurred within 1 year in all trials. This suggests excellent long-term safety even after 1 year in EES, and is consistent with the 5-year outcome noted in the SPIRIT III trial. ${ }^{16}$ In contrast, the incidence of ST in SES was numerically 3-4-fold higher than that in EES, and the rate of very late ST was also high. These results were also confirmed in the long-term LEADERS and PROTECT studies comparing SES with biolimus-eluting or zotarolimuseluting stents. ${ }^{17-19}$

Although this study was not powered to show differences in clinical outcome, these consistent trends across many safety outcome measures, along with the data from numerous randomized trials, suggest that EES may have safety benefit over SES in the long term, and that the safety concern of SES is mostly driven by late thrombotic events. Similar results have been suggested in a large prospective cohort study ${ }^{20}$ It is also consistent with a recent network metaanalysis indicating that EES has lower long-term mortality, MI, and ST rate than first-generation DES or even bare metal stents. ${ }^{8}$

There may be several factors that may explain the differences between the 2 stent platforms. First, the nature of the polymer is different. EES (Xience/Promus) is a fluorinated 
co-polymer-based stent composed of vinylidene fluoride and hexafluoropropylene, which has biocompatible and thromboresistant properties.21,22 Reduced inflammation and absence of hypersensitivity vasculitis was also observed in this biocompatible polymer-based stent. ${ }^{23}$ In contrast, SES has a polymer composed of poly n-butyl methacrylate and polyethylene vinyl acetate, which had a stronger inflammatory response up to 1 year in preclinical studies, compared with EES. ${ }^{24}$ Second, the stent design is different. Several preclinical studies have shown that thinner stent struts have less flow disturbance, greater endothelial cell coverage, and less thrombogenicity. ${ }^{22,23}$ The thicker strut thickness in SES (SES, $140 \mu \mathrm{m}$; EES, $81 \mu \mathrm{m}$ ) could also result in delayed endothelialization, inflammation, and late adverse events. Moreover, in the rheologic study, the higher number of link connectors in SES (SES, 6 links; EES, 3 links) increased areas of low wall shear stress in the stent, which could further accelerate thrombus formation and neointimal proliferation. ${ }^{25}$ Third, the anti-proliferative drug is different. Sirolimus has been known to inhibit smooth muscle cell proliferation more strongly than everolimus, ${ }^{\mathbf{2 6}}$ which explains the excellent efficacy of SES seen in this study. The drug load in EES, however, is more optimal than SES (EES, $88 \mu \mathrm{g}$; SES, $150 \mu \mathrm{g}$ ), and has better release kinetics. Considering that the effect of cytotoxic drugs on fibrin deposition was dose dependent in in vivo studies, ${ }^{27}$ the more frequent thrombotic events in SES may also be influenced by the amount and pharmacokinetics of coated drugs. This may be the reason why in the RESET optical coherence tomography substudy, stent struts not covered by neointima, malapposed struts, and intra-stent thrombi were more frequently observed in SES than in EES. ${ }^{28}$ Further, on pathology analysis after implantation of EES and first-generation DES, inflammation, fibrin deposition, and late thrombosis were also more frequent in the SES than in the EES group. ${ }^{23}$

Delayed arterial healing in SES seems to be associated with the development of late thrombotic events, increasing the rates of MI and even mortality. EES, in contrast, had favorable long-term efficacy and safety, and has shown the best performance among the stents used in current practice. Thus, EES should be the most important comparator in the development process after the second-generation DES era. In addition, efforts to improve late safety concerns (e.g., thinner struts, a more biocompatible polymer system, and more stabilized anti-proliferative drug control) while maintaining current efficacy would be important. Considering the RESET trial results, further studies are also warranted to determine the effect of procedural optimization, such as prolonged dual antiplatelet therapy and IVUS-guided PCI in selected patients, on long-term safety outcomes.

\section{Study Limitations}

This study was not powered to show differences in clinical outcomes. Thus, any positive findings or numerical differences observed in this study are hypothesis generating at best, and should be interpreted in the context of other trials of second-generation DES. In particular, because of the 3:1 randomization design, we need to be especially careful in interpretation of the SES group data. At the time of the study design, we wanted to obtain more data from the newly released EES. This led to the excessive dependence of the cumulative rate on the number of each events, especially for the SES group, making it difficult to interpret the comparative results. The possibility of underreporting cannot be completely ruled out, but as mentioned previously, rigorous efforts were undertaken to minimize possible biases. Given, however, that this is one of the major headto-head randomized trials in all-comers, the present 3-year outcomes could add important evidence, especially for the safety issue beyond 1 year after stent implantation.

\section{Conclusions}

At 3-year follow-up, efficacy endpoints including TLF were similar between EES and SES. EES showed a trend toward better safety profile, with the rate of cardiac death, target-vessel MI, and ST numerically lower than for SES. This effect was mainly driven by the lower risk of late thrombotic events beyond 1 year in EES. Due to the 3:1 randomization protocol, however, the difference in hard outcomes including all-cause death was possibly a chance finding, and should be interpreted with caution.

\section{Names of Grants}

This study was supported by a grant from the Clinical Research Center for Ischemic Heart Disease, Seoul, Korea (0412-CR02-07040001), and a grant from the Innovative Research Institute for Cell Therapy, Seoul National University Hospital (A062260), sponsored by the Ministry of Health, Welfare and Family, Korea.

\section{Acknowledgments}

The authors also received unrestricted grants from Abbott Vascular Korea and Boston Scientific Korea. The funding source had no role in study design, data collection, monitoring, analysis, interpretation, or writing of the manuscript.

\section{Disclosures}

The authors declare no conflicts of interest.

\section{References}

1. Moses JW, Leon MB, Popma JJ, Fitzgerald PJ, Holmes DR, O'Shaughnessy C, et al. Sirolimus-eluting stents versus standard stents in patients with stenosis in a native coronary artery. $N \mathrm{Engl}$ $J$ Med 2003; 349: 1315-1323.

2. Stefanini GG, Holmes DR Jr. Drug-eluting coronary-artery stents. $N$ Engl J Med 2013; 368: 254-265.

3. Jensen LO, Tilsted HH, Thayssen P, Kaltoft A, Maeng M, Lassen JF, et al. Paclitaxel and sirolimus eluting stents versus bare metal stents: Long-term risk of stent thrombosis and other outcomes: From the Western Denmark Heart Registry. EuroIntervention 2010; 5: 898-905.

4. Joner M, Finn AV, Farb A, Mont EK, Kolodgie FD, Ladich E, et al. Pathology of drug-eluting stents in humans: Delayed healing and late thrombotic risk. J Am Coll Cardiol 2006; 48: 193-202.

5. Stone GW, Rizvi A, Sudhir K, Newman W, Applegate RJ, Cannon LA, et al. Randomized comparison of everolimus- and paclitaxel-eluting stents: 2-year follow-up from the SPIRIT (Clinical Evaluation of the XIENCE V Everolimus Eluting Coronary Stent System) IV trial. J Am Coll Cardiol 2011; 58: $19-25$.

6. Baber U, Mehran R, Sharma SK, Brar S, Yu J, Suh JW, et al. Impact of the everolimus-eluting stent on stent thrombosis: A meta-analysis of 13 randomized trials. J Am Coll Cardiol 2011; 58: $1569-1577$.

7. Kang SH, Park KW, Kang DY, Lim WH, Park KT, Han JK, et al. Biodegradable-polymer drug-eluting stents vs. bare metal stents vs. durable-polymer drug-eluting stents: A systematic review and Bayesian approach network meta-analysis. Eur Heart J 2014; 35: 1147-1158.

8. Palmerini T, Benedetto U, Biondi-Zoccai G, Della Riva D, Bacchi-Reggiani L, Smits PC, et al. Long-term safety of drugeluting and bare-metal stents: Evidence from a comprehensive network meta-analysis. J Am Coll Cardiol 2015; 65: 2496-2507.

9. Park KW, Chae IH, Lim DS, Han KR, Yang HM, Lee HY, et al. Everolimus-eluting versus sirolimus-eluting stents in patients undergoing percutaneous coronary intervention: The 
EXCELLENT (Efficacy of Xience/Promus Versus Cypher to Reduce Late Loss After Stenting) randomized trial. $J$ Am Coll Cardiol 2011; 58: 1844-1854.

10. Cutlip DE, Windecker S, Mehran R, Boam A, Cohen DJ, van Es GA, et al. Clinical end points in coronary stent trials: A case for standardized definitions. Circulation 2007; 115: 2344-2351.

11. Park DW, Kim YH, Yun SC, Kang SJ, Lee SW, Lee CW, et al. Comparison of zotarolimus-eluting stents with sirolimus- and paclitaxel-eluting stents for coronary revascularization: The ZEST (comparison of the efficacy and safety of zotarolimuseluting stent with sirolimus-eluting and paclitaxel-eluting stent for coronary lesions) randomized trial. J Am Coll Cardiol 2010; 56: $1187-1195$.

12. Rasmussen K, Maeng M, Kaltoft A, Thayssen P, Kelbaek H, Tilsted $\mathrm{HH}$, et al. Efficacy and safety of zotarolimus-eluting and sirolimus-eluting coronary stents in routine clinical care (SORT OUT III): A randomised controlled superiority trial. Lancet 2010; 375: 1090-1099.

13. Kufner S, Byrne RA, Valeskini M, Schulz S, Ibrahim T, Hoppmann $\mathrm{P}$, et al. Five-year outcomes from a trial of three limus-eluting stents with different polymer coatings in patients with coronary artery disease: Final results from the ISAR-TEST 4 randomised trial. EuroIntervention 2016; 11: 1372-1379.

14. Shiomi H, Kozuma K, Morimoto T, Igarashi K, Kadota K, Tanabe K, et al. Long-term clinical outcomes after everolimusand sirolimus-eluting coronary stent implantation: Final 3-year follow-up of the Randomized Evaluation of Sirolimus-Eluting Versus Everolimus-Eluting Stent Trial. Circ Cardiovasc Interv 2014; 7: 343-354.

15. Jensen LO, Thayssen P, Christiansen EH, Maeng M, Ravkilde J, Hansen KN, et al. Safety and efficacy of everolimus- versus sirolimus-eluting stents: 5 -year results from SORT OUT IV. $J$ Am Coll Cardiol 2016; 67: 751-762.

16. Gada H, Kirtane AJ, Newman W, Sanz M, Hermiller JB, Mahaffey KW, et al. Five-year results of a randomized comparison of XIENCE V everolimus-eluting and TAXUS paclitaxeleluting stents: Final results from the SPIRIT III trial (clinical evaluation of the XIENCE V everolimus eluting coronary stent system in the treatment of patients with de novo native coronary artery lesions). JACC Cardiovasc Interv 2013; 6: 1263-1266.

17. Serruys PW, Farooq V, Kalesan B, de Vries T, Buszman P, Linke $\mathrm{A}$, et al. Improved safety and reduction in stent thrombosis associated with biodegradable polymer-based biolimus-eluting stents versus durable polymer-based sirolimus-eluting stents in patients with coronary artery disease: Final 5-year report of the LEADERS (Limus Eluted From A Durable Versus ERodable Stent Coating) randomized, noninferiority trial. JACC Cardiovasc Interv 2013; 6: 777-789.

18. Wijns W, Steg PG, Mauri L, Kurowski V, Parikh K, Gao R, et al. Endeavour zotarolimus-eluting stent reduces stent thrombosis and improves clinical outcomes compared with cypher sirolimuseluting stent: 4-year results of the PROTECT randomized trial. Eur Heart J 2014; 35: 2812-2820.

19. Maeng M, Tilsted HH, Jensen LO, Krusell LR, Kaltoft A,
Kelbaek H, et al. Differential clinical outcomes after 1 year versus 5 years in a randomised comparison of zotarolimus-eluting and sirolimus-eluting coronary stents (the SORT OUT III study): A multicentre, open-label, randomised superiority trial. Lancet 2014; 383: 2047-2056.

20. Raber L, Magro M, Stefanini GG, Kalesan B, van Domburg RT, Onuma Y, et al. Very late coronary stent thrombosis of a newer-generation everolimus-eluting stent compared with earlygeneration drug-eluting stents: A prospective cohort study. Circulation 2012; 125: 1110-1121.

21. Kukreja N, Onuma Y, Serruys PW. Xience V everolimus-eluting coronary stent. Expert Rev Med Devices 2009; 6: 219-229.

22. Kolandaivelu K, Swaminathan R, Gibson WJ, Kolachalama VB, Nguyen-Ehrenreich KL, Giddings VL, et al. Stent thrombogenicity early in high-risk interventional settings is driven by stent design and deployment and protected by polymer-drug coatings. Circulation 2011; 123: 1400-1409.

23. Otsuka F, Vorpahl M, Nakano M, Foerst J, Newell JB, Sakakura K, et al. Pathology of second-generation everolimuseluting stents versus first-generation sirolimus- and paclitaxeleluting stents in humans. Circulation 2014; 129: 211-223.

24. Nakazawa G, Finn AV, Ladich E, Ribichini F, Coleman L, Kolodgie FD, et al. Drug-eluting stent safety: Findings from preclinical studies. Expert Rev Cardiovasc Ther 2008; 6: $1379-$ 1391.

25. Koskinas KC, Chatzizisis YS, Antoniadis AP, Giannoglou GD Role of endothelial shear stress in stent restenosis and thrombosis: Pathophysiologic mechanisms and implications for clinical translation. J Am Coll Cardiol 2012; 59: 1337-1349.

26. Nashan B. Review of the proliferation inhibitor everolimus. Expert Opin Investig Drugs 2002; 11: 1845-1857.

27. Farb A, Heller PF, Shroff S, Cheng L, Kolodgie FD, Carter AJ, et al. Pathological analysis of local delivery of paclitaxel via a polymer-coated stent. Circulation 2001; 104: 473-479.

28. Kubo T, Akasaka T, Kozuma K, Kimura K, Kawamura M, Sumiyoshi T, et al. Comparison of neointimal coverage between everolimus-eluting stents and sirolimus-eluting stents: An optical coherence tomography substudy of the RESET (Randomized Evaluation of Sirolimus-eluting versus Everolimus-eluting stent Trial). EuroIntervention 2015; 11: 564-571.

\section{Supplementary Files}

\section{Supplementary File 1}

\section{Supplementary Methods}

Figure S1. Subgroup analysis of efficacy and safety outcomes.

Table S1. One-year landmark analyses of clinical outcomes in the intention-to-treat population

Table S2. DAPT status at 3 years

Please find supplementary file(s);

http://dx.doi.org/10.1253/circj.CJ-17-0677 